\title{
ОПЫТ ПЕРВОЙ МИРОВОЙ ДЛЯ СОВРЕМЕННОГО МИРОПОРЯДКА
}

The Next Great War? The Roots of World War I and the Risk of U.S.-China Conflict. ed. by R.N. Rosencrance, S.E. Miller. Cambridge MA: MIT Press, 2015. 290 p.

Следующая Великая война? Истоки Первой мировой войны И риск Конфликта междУ США И КИтаем. I Под ред. Р.Н. Розенкранц, С.Е. Миллер. Кембридж, Maccaчyсетс: MIT Press, 2015. 290 c.

В начале столетия мы наблюдаем противоречивые тенденции эволюции международной системы. С одной стороны, обостряется конкуренция между ведущей державой, доминировавшей на мировой арене несколько десятилетий, и быстро растущим претендентом на ее место. В результате ускоренной индустриализации последний уже сменил ее в качестве «мастерской мира», наращивает политическое влияние, модернизирует вооруженные силы. Ускоренные темпы строительства военно-морского флота укрепляют подозрения в том, что он планирует бросить вызов и ее традиционному преобладанию в Мировом океане. С другой стороны, ведушее государство сохраняет динамичную экономику и остается единственной по-настоящему глобальной державой, а ее конкурент, в первую очередь, заинтересован не в мировом господстве, а в сохранении благоприятных условий для собственного развития. Кроме того, международная повестка дня не исчерпывается соперничеством двух игроков; наряду с ними активную политическую роль играют несколько крупных государств, которые также участвуют в борьбе за укрепление безопасности, влияния и престижа. Эта конкуренция сдерживается небывалым уровнем взаимозависимости мировой экономики, а быстрое развитие технологий сулит увеличение процветания для всех народов. Человечество добилось беспрецедентных открытий в науке, в развитии средств коммуникации и транспорта, в результате все больше осознавая себя в качестве единой целостности.

Подобная картинка вполне согласуется с распространенными описаниями современного состояния глобальной среды. Но она с такой же мерой убедительности относится и к мировому порядку начала XX века. Конечно, названия стран придется поменять. Сто лет назад ведущей державой была Англия, а бросающим ей вызов претендентом Германия. Сегодня эти роли исполняют соответственно США и Китай. Тогда в качестве других влиятельных участников международного концерта выступали Россия, Франция, Австро-Венгрия, Италия. Первая сохранило свое привилегированное место и сегодня, но другие актеры мировой драмы сменились. В их числе теперь Бразилия, Европейский Союз, Индия, возможно, Япония.

В то же время схожих черт оказывается слишком много, чтобы избежать соблазна сравнений и построения аналогий. Сто лет

Статья подготовлена в рамках реализации гранта Российского гуманитарного научного фонда № 15-03-00728. 
назад конкуренция между великими державами вылилась в великую бойню, которую не остановили ни длительный опыт мирного сосуществования между ними, ни соображения экономической целесообразности, ни достижения человеческой культуры и гуманизма. Подобный результат ни тогда, ни сейчас не кажется предопределенным. Более того, история редко повторяется дословно. Вместе с тем опыт XX столетия побуждает осторожно подходить к идеалистическим описаниям крепнущей международной стабильности ${ }^{1}$.

В отечественном общественном сознании Первая мировая война традиционно остается в тени последовавшей революции и трагедии войны Великой отечественной. Мероприятия, посвященные столетней годовщина с момента ее начала, не поменяли ее в целом маргинального положения в российском восприятии истории. Для широкой общественности она остается далеким и по большей части забытым прошлым. На Западе отношение к ней совсем иное. Первая мировая война рассматривается как пролог ко всему кровавому и трагическому XX веку. В ней видят истоки и причины последующих конфликтов, революций, геополитических и идеологических столкновений. И это восприятие не только характерно для историков, но и проявляется в памяти о «Великой войне» на обыденном уровне.

Не удивительно, что к столетию трагедии 1914 г. было приурочено большое число публикаций, стремящихся разобраться в хитросплетениях европейской политики, приведших к столкновению ${ }^{2}$. Сборник, подготовленный Ричардом Розенкранцем и Стивеном Миллером, существенно отличается от традиционных работ этого жанра. Уже само название книги «Следующая Великая война? Истоки Первой мировой войны и риск конфликта между США и Китаем» свидетельствует, что те параллели между прошлым и настоящим, которые в исторической литературе всегда присутствуют, но остаются в тени, здесь оказываются в фокусе внимания.

Хотя в коллектив авторов вошли и историки (такие, как Ч. Майер, Т.Дж. Отто), в первую очередь издание решает аналитические и теоретические задачи. В вводной главе об этом говорится прямо: «цель настоящего издания - оглянуться назад, чтобы посмотреть вперед. Авторов просили исследовать истоки Первой мировой войны в поисках предупредительных знаков, уроков, предостережений или причинных связей, которые применимы (или могли бы быть таковыми) к современному международному порядку» (с. х).

К решению этой задачи были привлечены вполне адекватные ресурсы. Книга была подготовлена силами Белферовского центра исследований международной безопасности Гарвардского университета. Того самого, который выпускает "International Security" - наиболее влиятельный научный журнал по проблемам международной стабильности и порядка. К написанию статей были приглашены ведущие теоретики международных отношений, включая таких гуру, как Грэм Аллисон, Стивен ван Эвера, Джозеф Най, Джек Снайдер, Этель Солинген, Артур Стейн. Редакторами издания выступили известные специалисты Стивен Миллер и Ричард Розенкранц. Неожиданным в этом ряду ученых и аналитиков выглядит имя Кэвина Радда - в недавнем прошлом дипломата и премьер-министра Австралии. В то же время этот политик широко известен стремлением к аналитическому осмыслению практической деятельности и ее концептуальному обрамлению. Парадоксально, но он едва ли не единственный член авторского коллектива, специализирующийся на Китае и знающий китайский язык.

\footnotetext{
1 Пример оптимистичного видения современной международной системы дает недавняя книга американского теоретика Дж. Айкенберри [lkenberry 2011]

² Особенно стоит отметить, книгу британского историка Кристофера Кларка, которая представляется наиболее подробным, многогранным и неожиданным исследованием причин конфликта [Clark 2014]. Показательно, что Кларк уже в первой главе указывает на возможные параллели между предвоенной и сегодняшней ситуациями, а также неоднократно возвращается к ним по ходу изложения.
} 
Книга разделена на четыре части. В первой рассмотрены вопросы функционирования баланса сил и дипломатии. Вторая посвящена влиянию сдвигов в соотношении сил на международную стабильность. В третий раздел вошли статьи, освещающие влияние внутренней ситуации в странах на внешнюю политику. Наконец, четвертый содержит обобщающие сравнения состояния международной системы в начале XX и начале XXI веков. Таким образом, сборник оказывается не просто хаотичным набором статей, в нем прослеживается связующая логика, заключающаяся в переходе от непосредственного анализа внешней политики к изучению ее глубинных движущих сил и затем к систематическим обобщениям. Конечно, столь сложносоставное издание получилось не вполне ровным. Часть авторов ограничились короткими эссе, другие - пересказом известных концепций применительно к схематичному изображению событий 1914 года. В то же время ряд статей дают по-настоящему глубокий и неожиданный анализ.

В числе последних работа Артура Стейна, рассматривающая предвоенные кризисы с точки зрения стратегического поведения и теории игр. Автор утверждает - если в отдельных ситуациях совершение уступок в интересах поддержания мира воспринимается в качестве рациональной стратегии, то в повторяющихся играх страх эскалации с течением времени уступает недовольству, вызванному регулярными издержками стратегической сдержанности. Именно этим он объясняет ужесточение позиции Германии и России по инциденту в Сараеве после их дипломатических отступлений в двух марокканских и боснийском кризисах. С учетом предыдущих неудач у обеих стран присутствовало желание «отыграться», выдерживая жесткую позицию в надежде на то, что оппоненты пойдут на уступки первыми. Схожую точку зрения высказывает в своей статье и Джозеф Най, подчеркивая недопустимую легкомысленность оценки международнополитической ситуации в русле прошлых (даже недавних) кризисов. При этом он указывает на имевшее место восприятие возможного столкновения в 1914 г. через призму опыта ограниченной и относительно короткой франко-прусской войны 1870-1871 годов (с. 191).

Развивая анализ проблемы восприятия, Джек Снайдер обращается к известному парадоксу июльского кризиса 1914 года: представители обеих противоборствующих коалиций (Германия с одной стороны, Франция и Россия с другой) считали начало войны в 1914 г. предпочтительным вариантом по сравнению с откладыванием столкновения на более поздний срок. Подобная ситуация - вызов традиционной теории рационального выбора, так как один из игроков должен был ошибаться, считая, что результат конфликта окажется более благоприятным для него, чем для оппонента.

Прибегая к логике неоклассического реализма, Снайдер демонстрирует значение различий в восприятии обстановки накануне войны национальными элитами ведущих европейских стран. Он утверждает, что в условиях обострения конкуренции между великими державами, их оценка действий противоположной стороны может быть искажена, а фокус внимания переключиться с центральной проблемы поддержания собственной безопасности на периферийные озабоченности лояльностью и потенциалом своих союзников.

Один из редакторов сборника Ричард Розенкранц в своей статье сравнивает политику «баланса сил» со стратегией «сверхбалансирования», реализованной Отто фон Бисмарком в 1870-1890-х годах. С одной стороны, он, как и Снайдер, озабочен тем, что обязательства, данные слабому союзнику, могут привести к втягиванию великих держав в нежелательную конфронтацию (как это было с Сербией и Россией перед Первой мировой войной). С другой стороны, установление доверительных отношений или даже альянс с прямым конкурентом оказывается инструментом ограничения, если не преодоления враждебности между крупными государствами.

Так, после франко-прусской войны Бисмарк сформировал систему формаль- 
ных и неформальных договоренностей с Россией и Англией - державами, которые представляли наибольшую угрозу для молодой Германской Империи. Ее распад привел к образованию двух враждебных блоков, которые впоследствии и столкнулись в «Великой войне». Подобный анализ переворачивает традиционную логику неореализма относительно примата балансирования в отношениях между крупными державами [Waltz 1979] и подчеркивает роль политических лидеров в интерпретации структурных характеристик системы.

Схожее восхищение стратегическим гением германского канцлера демонстрирует и профессор Университета Торонто Алан Александрофф в статье, высвечивающей отличия его курса от дипломатии последователей. Критикуя идеалистические попытки Вудро Вильсона построить мир на всеобщем сотрудничестве и саморазрушительный экспансионизм Вильгельма $\mathrm{II}^{3}$, он отдает дань уважения эффективности системе концерта, возникшего сначала после Наполеоновских войн, а впоследствии реанимированного Бисмарком. Александрофф, вместе с тем, подчеркивает, что подобная эффективная система для своего поддержания требует либо наличие общей идеологии, либо искусной дипломатии, предполагающей сдержанность как в конкуренции, так и в обязательствах перед партнерами.

Хотя Розенкранц и не говорит об этом прямо, его анализ подразумевает, что в обозримом будущем Соединенным Штатам может быть полезнее пожертвовать интересами своих нынешних союзников и клиентов, прежде всего в Азии, для построения сотрудничества с Китаем. Александрофф же прямо указывает на необходимость оббяснения Японии пределов американской поддержки государства, придерживающегося провокационной линии в отношении КНР.

Если выводы Розенкранца относительно развития отношений между двумя круп- нейшими экономиками мира звучат подчеркнуто обнадеживающе, статья известного экономиста, профессора Гарвардского университета Ричарда Купера настраивает на менее оптимистические ожидания. Последний пересматривает популярную гипотезу о положительном влиянии взаимозависимости национальных хозяйств на сдерживание конфликтности в отношениях между странами. Действительно, в начале XX столетия интенсивность торговых и инвестиционных взаимодействий в глобальном масштабе достигла беспрецедентных значений (на этот же уровень они вернулись только во второй половине века). Известный публицист того времени Норман Энджел даже утверждал, что развитие такой тенденции приведет к исчезновению войн между цивилизованными народами [Angell 1910]. Уже следующее пятилетие после выхода его книги показало, насколько он был неправ.

Анализируя поведение европейских стран в преддверии кризиса, Купер отмечает, что внешнеэкономические интересы России способствовали формированию в стране «партии войны», которая выступала за скорейшее установление влияния над турецкими проливами. В условиях стремительного роста сельскохозяйственного экспорта, страна оказалась в критической зависимости от уязвимых транспортных коридоров, которые не контролировала. В результате «сельскохозяйственное лобби» сыграло большую роль в инициировании российской мобилизации в ответ на австро-венгерский ультиматум Сербии.

Хотя Купер предостерегает от проецирования российского опыта столетней давности на политику США и Китая (он отдельно подчеркивает, что Россия оставалась наименее интегрированной в мировой рынок крупной европейской экономикой /с. 69/), его анализ проблематизирует утвердившееся представление о стабилизи-

\footnotetext{
${ }^{3}$ Последний германский император. Спустя два года после прихода к власти отправил Бисмарка в отставку и перешел к реализации более агрессивной политики, построенной на убеждении в возросших экономических и военных возможностях Германии
} 
рующем влиянии глобализации. На схожие выводы наводит и статья Этель Солинген, которая изучает роль коалиции «железа и ржи» (союза крупных промышленников и сельскохозяйственной аристократии) в распространении «гипернационализма» и милитаризации Германии начала XX века. Рост зависимости страны от мировой экономики привел к консолидации наиболее консервативных слоев германского общества в рамках аграрно-индустриально-военного комплекса. Отталкиваясь от этого опыта, Солинген подчеркивает необходимость учета внутриполитического контекста при оценке влияния внешнеэкономических связей на поведение страны на международной арене.

Сразу три статьи Грэма Аллисона, Дэвида Ричардса и Чарльза Майера посвяшены оценке вероятности попадания современной международной политики в «ловушку Фукидида». В основе этой популярной в западной литературе метафоры лежит анализ древнегреческого историка последствий подъема Афин для системы городов-полисов. Рост конкурента поколебал существовавшую гегемонию Спарты и вылился в серию ожесточенных войн, опустошивших Грецию.

Столкновение между доминирующей державой и претендентом на этот статус представляется одним из наиболее распространенных сюжетов в истории международных отношений. Вместе с тем открывающий этот раздел книги Аллисон уверен урок Пелопонесской войны не в том, что конфликт между США и Китаем неизбежен, а в том, что поддержание мира потребует усилий и сдержанности с обеих сторон. Вместе с тем он считает, что современные государства лучше подготовлены к политике балансирования на грани, чем древнегреческие полисы. Между тем Кэвин Радд в одной из заключительных работ сборника предупреждает против стратегической самоуспокоенности, распростра- нившейся после окончания «холодной войны». Соглашаясь с основным посылом Аллисона, он утверждает, что сохранение мира не происходит автоматически, оно требует гибкой дипломатии, креативности политического руководства и эффективных институтов.

Другой практик, независимый аналитик и бизнесмен Дэвид Ричардс, напротив, уверен, что современная международная система принципиальным образом отличается (и в лучшую сторону) как от мира городовполисов, так и от Европы в 1914 году. Он обращает внимание на сдерживающую роль ядерного оружия, экономической глобализации и зависимости политических лидеров от демократической легитимации, которые препятствуют развязыванию безответственных конфликтов между великими державами. Схожие оптимистичные оценки высказывает и Джозеф Най в уже упомянутой статье. Он также делает акцент на отсутствие «идеологии войны» в современном мире, тогда как в начале XX века мировидение многих европейских политиков определялось дарвинистской концепцией борьбы за выживание (сс. 190-191).

Наконец, наиболее пессимистичные оценки относительно «ловушки Фукидида» высказывает Майер. Он, как и Розенкранц и Снайдер, обращает внимание на роль альянсов, связывающих крупных игроков и заставляющих вступать в войны, которых они хотели бы избежать. Так было и в описанной Фукидидом истории противостояния Афин и Спарты, и в начале XX века, когда все ведущие государства (за исключением относительно слабой Италии) чувствовали себя связанными обязательствами перед союзниками ${ }^{4}$. Одновременно Майер дополняет выводы Розенкранца, обращая внимание на дилеммы восприятия угроз безопасности, характерные для крупных держав, а также на конкурентный характер отношений внутри альянсов. Его анализ подчеркивает трудности на пути достиже-

\footnotetext{
4 Эта проблема стал предметом изучения в классической работе Томаса Кристенсена и Джека Снайдера [Christensen, Snyder 1990] и с тех пор остается одной из наиболее обсуждаемых в американском исследовательском дискурсе.
} 
ния компромисса между США и Китаем, что несколько контрастирует с оптимистичным настроем большинства статей.

Наряду с уже упомянутой работой Этель Солинген к проблематике взаимосвязи внутренней и внешней политики обращаются Т.Дж. Отто и Стивен ван Эвера. Первый рассматривает динамику внутриполитической ситуации в непосредственном преддверии войны в ее основных будущих участниках (в то время как Солинген берет более широкий временной срез). Он отмечает, что в каждой из стран наблюдались черты политического кризиса, хотя и различной природы. Сложная внутренняя ситуация влияла на стратегические решения руководителей государств во внешней политике, хотя и не играла определяющей роли.

Выводы Отто из анализа исторического опыта для современности контрастируют с упрощенными схемами адептов концепции «демократического мира». Он подчеркивает, что экономический подъем Китая не обязательно приведет к установлению плюралистического режима в стране, а ослабление контроля коммунистической партии может оказаться не меньшей угрозой, чем открытый ревизионизм КНР. По его мнению, внутренняя дестабилизация крупной страны - один из наиболее серьезных источников опасности для международной системы.

Несколько отличную оценку влияния внутриполитической конъюнктуры дает один из крупнейших американских специалистов в области стратегического анализа Стивен ван Эвера. Он концентрирует внимание на роли военного истеблишмента в провоцировании Первой мировой войны. Доминировавшая среди их представителей уверенность в неоспоримом превосходстве наступательных действий над оборонительными, в априорной взаимной враждебности стран и действенности политики запугивания, а также в ценности империй и благородной природе войны, побуждала их к поддержке наиболее агрессивных настроений. Между тем слабость гражданских правительств означала подчинение политики целям военной стратегии.
Ван Эвера подчеркивает (и в этом он сходится с Наем), что сегодня как в США, так и в Китае «культ наступления» отсутствует, а вооруженные силы находятся под эффективным контролем политических руководителей. Подобный анализ позволяет ему сделать оптимистичные выводы о перспективах поддержания мира между ними. Среди современных государств аналог европейских держав начала прошлого века он все же находит. В таком качестве, по его мнению, выступает Пакистан. Исламабад с учетом недееспособного состояния своей политической системы, влияния армии на государственную власть и дарвинистской картины мира, преобладающей в военном истеблишменте, оказывается наиболее последовательным носителем агрессивных устремлений среди современных крупных государств.

В заключении сборника Ричард Розенкранц, систематизируя основные выводы его авторов, отмечает недостаточность структурных объяснений причин Первой мировой войны. Сами по себе распределение сил в международной системе, конкуренция между гегемоном и претендентом на этот статус или особенности политических режимов, вовлеченных стран, не вели к конфликту неизбежно. Реальная ситуация в Европе 1914 г. была сложнее, чем упрощенные схемы, предлагаемые крупными макротеориями. Соединение множества движущих сил способствовала развязыванию конфликта, но события могли развернуться по-другому, если бы политики, военные, дипломаты сделали другой выбор на множестве развилок, которые предшествовали кризису. Европе потребовалось две мировые войны, чтобы сформировать устойчивую систему институтов, позволившую преодолеть эту «тиранию маленьких вещей», как называет ее Розенкранц (с. 216), и добиться стабильного мира, не зависящего от амбиций и просчетов руководителей стран.

В отношениях США и Китая рассчитывать на построение схожего комплекса правил, эффективно ограничивающих враждебность и конкуренцию сегодня, бы- 
ло бы наивным. В этой связи аналогии между Европой начала XX века и Азией XXI столетия представляются оправданными. В то же время попытки автоматически перенести на сегодняшнюю действительность логику конкуренции Великобритании и Германии - опасное упрощение. Книга выступает предостережением от подобных интеллектуальных манипуляций. В ней глубоко разбирается влияние стратегических, внутриполитических, экономических переменных, а также значение отдельных личностей и доминирующих идейных конструктов, на вероятность конфликтов между крупными международными игроками. Без учета особенностей в каждом из этих измерений, прямые параллели между прошлым, настоящим и будущим оказываются некорректными.

Конечно, представленный сборник при всем многообразии теоретических и методологических подходов авторов отражает явную, но в то же время ограниченную позицию. Несмотря на наличие выразителей «особого мнения», большая часть книги настраивает на успокаивающий лад, подчеркивая многочисленные различия между Европой 1914 г. и современной ситуацией. В этой связи показательно отсутствие в числе авторов издания исследователей, придерживающихся более настороженных позиций. Прежде всего, Джона Миршаймера - известного теоретика, который не раз выражал уверенность в том, что подъем Китая не будет происходить мирно, оперируя как раз структурными объяснениями [Mearsheimer 2014: 360-411].

Кроме того, необходимо учитывать, что издание сформировали работы представителей американского (или шире англосаксонского) интеллектуального истеблишмента. В этой связи анализ исторических аналогий проводится через призму американских интересов и стратегических решений, которые предстоит принять Соеди- ненным Штатам в ближайшие годы. Показательно и то, что в его написании приняли участие специалисты по истории дипломатии, международной политике, стратегическим исследованиями, но в их числе (мы это уже отмечали) практически нет специалистов по Китаю. Ряд авторов обращают внимание на значение национальной культуры в формировании политического курса, но в отсутствие регионоведческих компетенций, анализ страдает недостатком конкретики при приложении теоретических построений к современным реалиям.

В то же время получившаяся книга вносит весомый содержательный вклад в дискуссию о современном состоянии международной системы. Она демонстрирует растущую озабоченность американского экспертного сообщества по поводу нарастания конкуренции в международной системе. Очевидно, что в центре его опасений находится не вероятность формирования полицентричного мира, о которой часто говорят отечественные аналитики и руководители, а усилиние конкуренции со стороны одной страны - Китая.

Кроме того, научная фундированность издания, участие в его подготовке крупнейших ученых-международников и рассмотрение исторического нарратива с различных интеллектуальных позиций превращает его еще фактически в готовое пособие по современной теории международных отношений. Оно может быть интересно не только специалистам по Соединенным Штатам и истории дипломатии, но и тем, кто занимается вопросами международного порядка, стабильности или просто стремится углубить свои представления об актуальном состоянии международно-политической мысли.

Игорь Истомин кандидат политических наук

\section{Список литературы}

Angell $N$. The great illusion; a study of the relation of military power in nations to their economic and social advantage. London: G. P. Putnam's sons, 1910. 388 p. 
Christensen T. J., Snyder J. Chain gangs and passed bucks: Predicting alliance patterns in multipolarity / / International Organization. - 1990. - Vol. 44, No. 02. P. 137-168.

Clark Ch. The Sleepwalkers. How Europe went to war in 1914. London: Allen Lane, 2012. 696 p.

Ikenberry G.J. Liberal leviathan: The origins, crisis, and transformation of the American world order. N.Y.: Princeton University Press, 2011. $372 \mathrm{p}$.

Mearsheimer J.J. The Tragedy of Great Power Politics. Second Edition. N.Y.: W. W. Norton \& Company, 2014. $561 \mathrm{p}$

Waltz K.N. Theory of International Politics. Boston: McGraw-Hill, 1979. 251 p.

\section{References}

Angell N. (1910). The great illusion; a study of the relation of military power in nations to their economic and social advantage. London: G. P. Putnam's sons. 388 p.

Christensen T. J., Snyder J. (1990). Chain gangs and passed bucks: Predicting alliance patterns in multipolarity. International Organization. Vol. 44. No. 02. P. 137-168.

Clark Ch. (2014). The Sleepwalkers. How Europe went to war in 1914. N.Y.: Harper Perennial. 696 p.

Ikenberry, G. J. (2011). Liberal leviathan: The origins, crisis, and transformation of the American world order. N.Y.: Princeton University Press. 372 p.

Mearsheimer, J.J. (2014). The Tragedy of Great Power Politics. Second Edition. N.Y.: W. W. Norton \& Company. $561 \mathrm{p}$.

Waltz K.N. (1979). Theory of International Politics. Boston: McGraw-Hill. 251 p. 